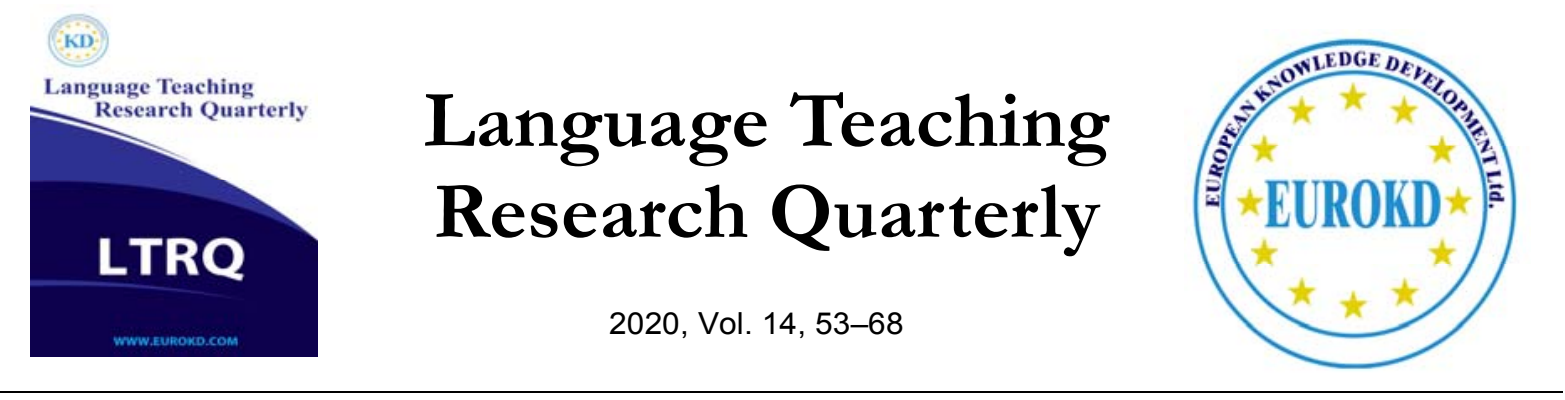

\title{
Are Paragraph Theories Array of Impressions?
}

\author{
Edward Owusu \\ Senior Lecturer of English language, Department of Communication Studies, and Ag. Director, Quality \\ Assurance and Academic Planning Directorate, Sunyani Technical University, Sunyani, Ghana
}

Received 14 June 2019 Accepted 11 November 2019

\begin{abstract}
There are a number of functions paragraphs play in discourse studies. For example, it encourages a writer to give adequate focus to the various aspects of his or her message; and it facilitates the identification of one idea in an essay to another idea. Some classical second language writers (for example: Stern, 1976; Halliday \& Hasan, 1976; Warriner, 1988; Lunsford \& Connors, 1995; Driscoll \& Brizee, 2000; Langan, 2001; Sekyi-Baidoo, 2003; Kirzner\& Mandell, 2007; and Beare, 2012) on discourse studies have focused on key theoretical issues of paragraph theory such as: definition, types, structure and elements. Modern writers such as Bailey (2011), Rolls \& Wignell (2013), Nordquist (2019) have also contributed to studies on paragraph theory. Some university students find it perplexing observing all the elements and constituents of the paragraph theory. The purpose of the paper was, therefore, to find out factors accounting for students' problems in construction of paragraphs. This chronological paper traced the various theories of paragraph from 1970s to the 2000s, and analysed thirty (30) essay-based texts of university students in a descriptive way. Again, two texts (one each) from a non-native academic of English and a native academic of English were analysed. The results from the texts of student participants showed students' paragraph writing flaws in areas of concluding sentence, and coherence. The study, therefore, recommended that second language teachers should pay extra attention to students' paragraphs, especially in writing of concluding sentences, and observance of paragraph coherence.
\end{abstract}

Keywords: Paragraph Theory, Topic Sentence, Paragraph Unity, Coherence, Paragraph Completeness.

\section{Introduction}

The teaching and learning of English writing, composition or essay in the departments of most private universities in Ghana, is captured by courses like: Business Communication, Communication Skills I and II, English Language I and II; and Writing Skills I and II. English 
language lecturers, therefore, have responsibility of taking students through the rudiments of these write-ups. One of these rudiments is paragraphing. Theories of paragraph are significant part of studies such as discourse, summary, essay, letter, report, critical review, and research. In this paper, a variety of ideas on paragraph theories have been discussed. The design of the paper is mainly focused on earlier classical works of Stern (1976), Halliday and Hasan (1976), Warriner (1988), Lunsford \& Connors (1995), Driscoll \& Brizee (2000), Langan (2001), SekyiBaidoo (2003), Kirzner \& Mandell (2007), and Beare (2012). The study is also based on relatively recent works of Bailey (2011), Rolls \& Wignell (2013), and Nordquist (2019a, 2019b).The paper is segmented into eight parts. These are: introduction, literature review, research methods, analysis of data, findings and discussions, recommendations, conclusion, and references.

\section{Literature Review}

The review of literature focuses on paragraph theory. For the purpose of this study, paragraph theory is used in reference to combined sub-topics of paragraph definition, types, structure, and elements:

\section{Paragraph Defined}

The paragraph is pivotal in discourse studies. Without it, an essay will be a solitary entity without partitions. Hence, the reader is likely to lose track of the ideas being discussed, if no paragraphs are introduced. Earlierdefinitions of paragraph by authorities, and writers such as Stern (1976); Warriner (1988); Lunsford \& Connors (1995); Langan (2001); and Driscoll \& Brizee (2010) are equivalent although different in nature. This oxymoronic statement depicts that while some of the definitions are comparable, others possess conflicting ideas.

Paragraph has been defined by Stern (1976): "as a sequence of structurally related sentences." To Warriner (1988, p. 43): "it is a group of closely related sentences." Both Warriner (1988) and Stern's (1976) argue that a paragraph is a group of analogous sentences. Conversely, these definitions are contentious especially when a reader comes across a one-sentence paragraph in a write-up. Such an experience has the predisposition of bewildering a naïve reader. The feasible question that can emerge is: can a paragraph be made up of a single sentence? The response, obviously, is a yes or no situation. If it is a yes, why has both Stern (1976) and Warriner (1988) defined paragraph as '... related sentences?' Because their definition presupposes that a paragraph can never be made up of only a sentence. On the other hand, if the response is a no, why do Lunsford \& Connors $(1995$, p. 116) define paragraph as: '.. a group of sentences or a single sentence that forms a unit?'

We have seen in our earlier two definitions by Stern (1976) and Warriner (1988) that 'a paragraph is a group of or a sequence of structurally/closely related sentences.' But, Lunsford and Connors' definition shows that a paragraph can be made up of a single sentence which is part of a component of writing. So, why is Lunsford and Connors' definition dissimilar from Stern's and Warriner's? Or can we say that Lunsford and Connors' definition is an improvement on Stern's and Warriner's whose definition came up in 1976 and 1988 respectively? 
Langan (2001, p. 5) however, sees a paragraph as a short paper of around 150 to 200 words which consists of an opening called a topic sentence followed by a series of sentences which support that point.

Bailey (2011, p. 78) defines a paragraph as a group of sentences that deal with a single topic. Bailey (2011) has also stated that, though the length of paragraphs varies significantly according to text type, they should not be less than four or five sentences. This contradicts earlier definition of Langan (2001) that defines a paragraph as a short paper of around 150 to 200 words. This contradiction sometimes creates confusion in the minds of learners.

According to Nordquist (2019a), the purpose of every paragraph is to give an indication about a swing in thinking, and also give readers a rest. Thus, a paragraphis created to signal an introduction of a new line of thinking in a discourse.

\section{Types of Paragraph}

Various writers have contradictory views on this topic. Despite the fact that the three traditional types of paragraph are: introduction, body and conclusion, Kirzner \& Mandell (2007) have stated that writers use four types of paragraphs: Introductory, Body, Transitional and Concluding paragraphs in their write-ups. In an essay, each of these paragraphs serves a special purpose:

Introductory paragraphs identify an essay's topic, give basic background or contextual information, and indicate the writer's purpose for writing, approach the topic (including the scope of treatment), and thesis statement (Kirzner \& Mandell, 2007).

Body paragraphs provide the main development and support of an essay's main idea or thesis (Kirzner \& Mandell, 2007). The writer uses body paragraphs to develop the content of the essay and handle the diverse ideas that the writer wants to focus on.

Transitional paragraphs connect the various body paragraphs together and join the body of an essay to the introduction and conclusion (Kirzner \& Mandell, 2007). Thus transitional paragraphs act as signposts that guide readers to the next part of their essay.

Concluding paragraphs review an essay's main points, discuss the significance of those points, and sometimes point ahead to future treatments of the topic. (Kirzner \& Mandell, 2007). It is the conclusion of an essay that handles the concluding paragraphs. The concluding paragraphs buttress the essential idea of a work and leave readers satisfied.

Warriner (1988, p. 79) on the other hand, argues that most paragraphs can be grouped into four types, according to the writer's main purpose, or reason, for writing. And these types are: narrative, descriptive, expository, and persuasive. I find it intricate accommodating these groupings of Warriner as clear-cut types of paragraphs. Instead, I see them as some of the various ways of writing compositions. Consequently, Langan (2001) does not consider Warriner's (1998) categorization of paragraphs as 'types' per se. Instead, he argues that they are patterns of essay development.

Sekyi-Baidoo (2003) has also discussed types of paragraphing as organic/inorganic and mainstream/structural. On organic and inorganic paragraphs, he argues that organic paragraphs are the ones that exhibit unity and coherence (Sekyi-Baidoo 2003, p. 143). By this, he classifies 
types of paragraphs by using two of the elements of paragraphs (unity and coherence) as pointed out by some authors (for example: Rosen \& Behrens, 1997; Warriner, 1988; Forlini et al., 1987; Childs et al., 1999; Langan, 2001; Bauman, 1991; Carroll et al., 2001; and Driscoll \& Brizee 2010). Inorganic paragraphs, according to him, are those paragraphs that do not possess the quality of unity and coherence (Sekyi-Baidoo, 2003, p. 143). This is where the confusion lies. If we are to go by this taxonomy, how do we term paragraphs with or without the third element adequacy of development or satisfaction of coverage - which has proponents such as Rosen \& Behrens (1997), Driscoll \& Brizee (2010), and ironically Sekyi-Baidoo (2003) himself? SekyiBaidoo (2003) again differentiates paragraphs by their position and function in the discourse. Under this focus, he discusses mainstream and structural paragraphs. To him, the introductory, concluding and the transitional paragraphs are called structural paragraphs. They are so called because they do not discuss any particular point or issue. Mainstream paragraphs on the other hand contain topics or issues which are part of the concerns of the topic as a whole (SekyiBaidoo, 2003). Thus, this type of classification recognizes body paragraphs as mainstream since they contain issues which are core to the topic under discussion as a whole; and introductory, transitional and concluding paragraphs as structural because they do not talk about any particular subject matter or issue.

\section{Paragraph Structure}

Structure is the physical form or shape of an entity. In paragraphing, structure refers to composition of sentences into paragraphs. In this section, we discuss some opinions of a number of authorities and writers on paragraph structure. According to Forlini et al. (1987), Warriner (1988) Childs et al. (1999), Beare (2012), Rolls \& Wignell (2013)and Nordquist (2019a) the basic components of a paragraph are: topic sentence, supporting sentences and concluding sentence. The topic sentence is the sentence in the paragraph that presents the main idea, which all the other ideas in the paragraph support or explain (Forlini et al., 1987; Warriner, 1988; Childs et al., 1999; Beare, 2012; Rolls \& Wignell, 2013, Nordquist, 2019). The point is every paragraph is supposed to talk about one main idea or concept, and it is the topic sentence that captures this main idea. Often, in a paragraph, the topic sentence is the first sentence (Warriner, 1988). In this position, it tells the reader immediately what the paragraph is about (Warriner, 1988). The topic sentence can also appear in the middle or at the end of a paragraph (Warriner, 1988). Driscoll \& Brizee (2010) also confirm Warriner's (1988) claim and aver that it can occur anywhere in the paragraph (as the first sentence, the last sentence, or somewhere in the middle); but, an easy way to make sure a reader understands the topic of the paragraph is to put the topic sentence near the beginning of the paragraph.

The authors again go on to say that a paragraph should also have supporting sentences. To Warriner (1988) these supporting sentences give specific information that supports the main idea in the topic sentence. They provide specific explanations and support for the topic sentence of a paragraph (Beare, 2012). Thus, the supporting sentences are the structures that develop the key idea of each paragraph. Forlini et al. (1987, p. 443-446) therefore reason that paragraphs may be 
developed with examples, details, facts, reasons, and incidents. When you develop a paragraph with examples, it means, you show specific instances of some general idea (Forlini et al., 1987, p. 443). While details are pieces of descriptive information, facts are specific pieces of information that are true (Forlini et al., 1987, p. 443). When supporting sentences give reasons it means they can be used to answer any questions raised by the main idea, and if the topic sentence presents an opinion, reasons can also help to defend that opinion (Forlini et al., 1987, p. 445). Supporting sentences that are written in an incident format, give brief story or set of events offered to illustrate a main idea (Forlini et al. 1987, p. 446). So, by inference a supporting sentence could narrate, describe, show example, or illustrate.

The concluding sentence is the third component. A concluding sentence concludes the paragraph. Warriner (1988) uses clincher to refer to concluding sentence. According to him, this is the sentence that gives a paragraph a sense of completeness; it emphasises the main idea by restating the idea in different words (Warriner, 1988). So, in concluding a paragraph, it is important for the writer to recapitulate the core idea stated in the topic sentence; and this is done well if synonymous are used to state the idea in one's own way.

\section{Elements of Paragraph}

Apart from the structure, a paragraph should have some essentials. For a paragraph to be effective, it must also have three characteristics - unity, coherence (Rosen \& Behrens, 1997; Warriner, 1988; Forlini et al., 1987; Childs et al., 1999; Langan, 2001; Bauman, 1991; Carroll et al., 2001; Driscoll and Brizee, 2010; Sekyi-Baidoo, 2003) and completeness (Rosen \& Behrens, 1997; Driscoll \& Brizee, 2010, Sekyi-Baidoo, 2003).

On unity, Warriner (1988, p. 48) argues that "Every sentence in a paragraph should be directly related to the main idea." By this we say the sentences are united. Thus, a paragraph contains harmony when all sentences refer to the main idea or thesis of the paper (Rosen \& Behrens 1997, p. 119). Forlini et al. (1987, p. 447) opine that "a paragraph has unity when all of the supporting ideas in the paragraph work together to develop the topic sentence. This is a realistic declaration; but, what about a one-sentence paragraph which does not have supporting sentences? Can we say such a paragraph lacks unity? Or do we say its unity is inherent in the one-sentence paragraph itself?

Another vital feature of an effective paragraph is coherence. Halliday \& Hasan (1976) think that "the concept of cohesion is a semantic one; it refers to relations of meaning that exist within the text, and that define it as a text." Coherence therefore occurs where the interpretation of some elements in the discourse is dependent on that of another (Halliday \& Hasan, 1979). Thus, it is the kind of relation that exists between one entity in discourse and other elements that are vital to its elucidation. In this case, coherence helps to create symbiotic relationship between grammatical structures.

In a coherent paragraph, ideas are arranged in a clear order and are connected smoothly (Warriner, 1988, p. 50). Coherence, consequently,is the trait that makes the paragraph easily understandable to a reader (Driscoll \& Brizee, 2010). Without it, it becomes difficult for one to 
grasp or fathom what a writer wants to put across. Coherence is created when one builds logical and verbal bridges in a paragraph (Driscoll \& Brizee, 2010).

Another attribute of effective paragraph is completeness (adequate development) (Rosen \& Behrens, 1997, p. 119). This means that every idea discussed in the topic sentence should be adequately explained and supported by evidence and details that work together to explain the paragraph's controlling idea (Rosen \& Behrens, 1997, p. 119). When this is not done, the writer creates the opportunity for a lot of questions to be asked. Accordingly, to avoid writing sweeping statements, all claims should be duly substantiated. When claims are substantiated, then it means all issues have been satisfactorily covered. And this also makes a paragraph effective. But it is not possible to expatiate ideas when one's paragraph is made up of only a sentence. In an attempt to address these gaps, the paper seeks to find answers for the following research questions:

$\mathbf{R Q}_{1}$ : Do the essays of students possess introduction and conclusion?

$\mathbf{R Q}_{2}$ : Do the paragraphs of students have topic sentences, which have been developed with supporting and concluding sentences?

$\mathbf{R Q}_{3}$ : Do the paragraphs in students' composition possess coherence, completeness, and unity?

$\mathbf{R Q}_{4}$ : Are paragraph theories mere collection of ideas?

\section{Methods}

\section{Research Design}

Qualitative research design was employed for this study. Seliger and Shohamy (2001, p. 116) argue that qualitative research is also concerned with description, which "involves a collection of techniques used to specify, delineate, or describe naturally occurring phenomena without experimental manipulation." Therefore, I developed an analytical framework (please see Figure 1) which I used in analyzing the scripts of the participants in a descriptive way.

\section{Participants and Sampling Techniques}

Thirty (30) 1st and 2nd year students from the 2011/2012 academic year-batch of Ghana Baptist and Christian Service University Colleges were randomly selected and used as participants for the study. Out of this, 20 were from Christian Service University College (CSUC), and 10 were from Ghana Baptist University College (GBUC). They were in the age ranges of 19 and 32. While 12 of the participants were female students, 18 of them were male students. These participants were studying various programmes options in Business Administration.

\section{Instruments}

Classroom-based and take-home texts were used in collecting data from the participants. The class-room based texts (which were on narrative and cause and effect essays) were sampled from end of first semester examination (2011/2012 Academic Year) scripts of level 200 students of Christian Service University College (CSUC); and Mid-Semester Examination scripts of level 100 students (January 2012 session) of Ghana Baptist University College (GBUC). The 
participants were also tasked to do take-home exercises (on argumentative, descriptive, and comparison and contrast essays) with a duration of 7 days.

\section{Data Analysis}

The framework used in analyzing the data collected was Essay Analytical Framework (EAF). This framework (please see Figure 1) has 3 main variables. They are: the structure of the essay, the paragraph theory, and methods of development. However, only variables 1 and 2 were used in assessing the data collected from the field, since they contain issues the research questions sought to answer. Though in variable 1 has thesis statement, the analysis of data in this paper did not cover that. Owusu \& Adade-Yeboah (2014) have done a study on thesis statement. Again, Adade-Yeboah \& Owusu (2016) have conducted another study using the variable 3 of the framework.

Thesis Statement

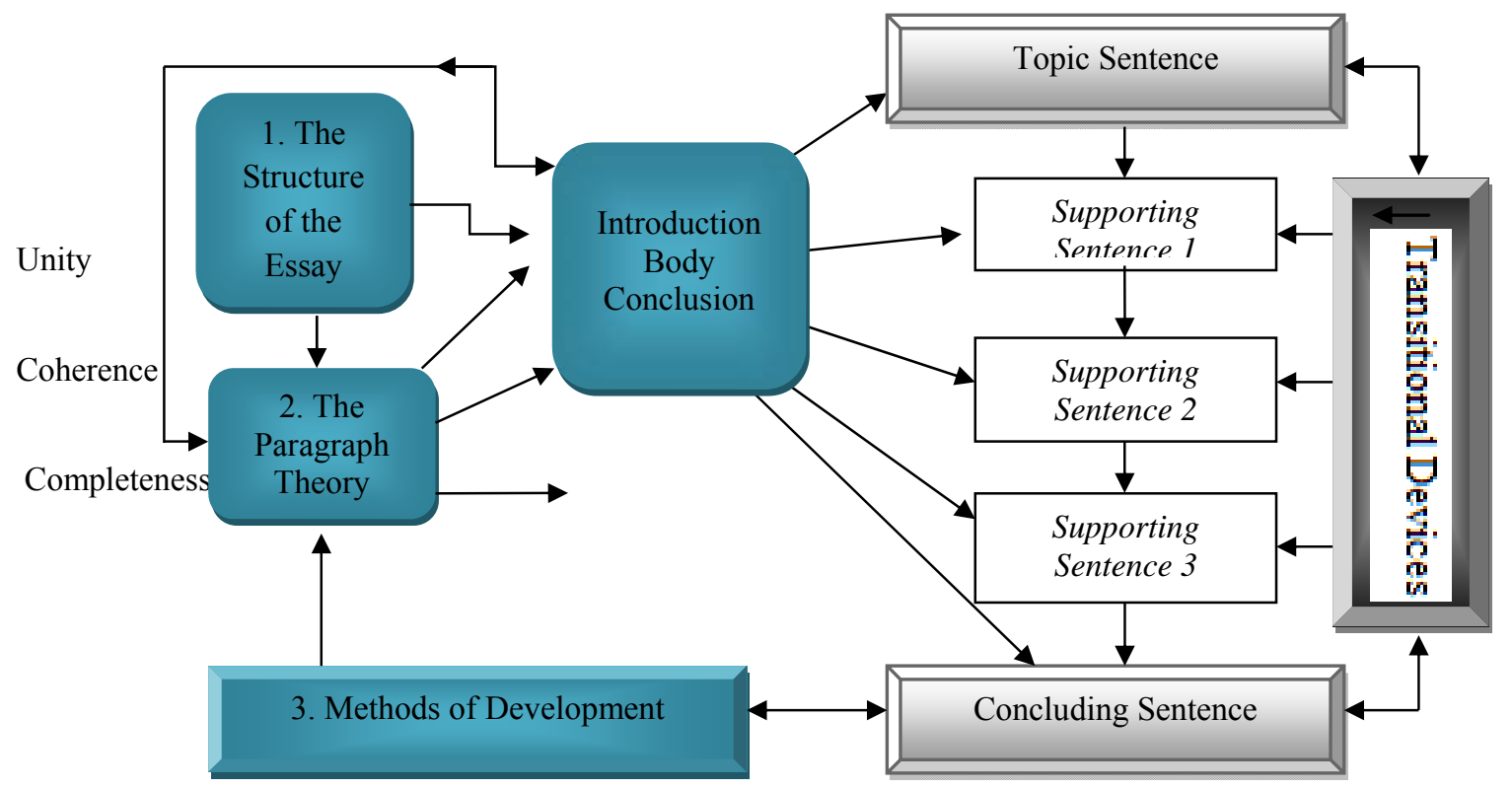

Figure1. Essay Analytical Framework (EAF) Owusu (2012).

\section{Analysis of Classroom Data}

Here, all the 30 scripts collected from the students have been analysed. This analysis answers research questions 1 and 2 . 
Table 1

Analysis of data collected from student participants

\begin{tabular}{|c|c|c|c|c|c|}
\hline $\begin{array}{l}\text { PARAGRAPH } \\
\text { ISSUES } \Rightarrow \\
\text { TEXTS }\end{array}$ & $\begin{array}{l}\text { ESSAY } \\
\text { STRUCTURE } \\
\text { (In \& Con) }\end{array}$ & $\begin{array}{l}\text { PARAGRAPH } \\
\text { THEORY } \\
\text { (TS, SS \& CS) }\end{array}$ & $\begin{array}{l}\text { UNITY } \\
\text { (U) }\end{array}$ & $\begin{array}{l}\text { COHERENCE } \\
\text { (Coh) }\end{array}$ & $\begin{array}{l}\text { COMPLETENE } \\
\text { SS } \\
(\text { Comp) }\end{array}$ \\
\hline TEXT 1 & $\begin{array}{l}\text { In }-X \\
\text { Bo }-\varnothing \\
\text { Con }-X\end{array}$ & $\begin{array}{l}\mathrm{TS}-\sqrt{ } \\
\mathrm{SS}-\emptyset \\
\mathrm{CS}-\sqrt{ }\end{array}$ & $U-\sqrt{ }$ & Coh $-\mathrm{X}$ & Comp $-\sqrt{ }$ \\
\hline TEXT 2 & $\begin{array}{l}\text { In }-\sqrt{ } \\
\text { Bo }-\sqrt{ } \\
\text { Con }-X\end{array}$ & $\begin{array}{l}\mathrm{TS}-\sqrt{ } \\
\mathrm{SS}-\sqrt{ } \\
\mathrm{CS}-\mathrm{X}\end{array}$ & $U-X$ & Coh $-\mathrm{X}$ & Comp - X \\
\hline TEXT 3 & $\begin{array}{l}\text { In }-\sqrt{ } \\
\text { Bo }-\sqrt{ } \\
\text { Con }-\sqrt{ }\end{array}$ & $\begin{array}{l}\mathrm{TS}-\varnothing \\
\mathrm{SS}-\sqrt{ } \\
\mathrm{CS}-\mathrm{X}\end{array}$ & $U-X$ & Coh $-\mathrm{X}$ & Comp - X \\
\hline TEXT 4 & $\begin{array}{l}\text { In }-\sqrt{ } \\
\text { Bo }-\sqrt{ } \\
\text { Con }-\varnothing\end{array}$ & $\begin{array}{l}\mathrm{TS}-\varnothing \\
\mathrm{SS}-\sqrt{ } \\
\mathrm{CS}-\varnothing\end{array}$ & $U-\sqrt{ }$ & Coh $-\mathrm{X}$ & Comp $-\sqrt{ }$ \\
\hline TEXT 5 & $\begin{array}{l}\text { In }-\sqrt{ } \\
\text { Bo }-\sqrt{ } \\
\text { Con }-\varnothing\end{array}$ & $\begin{array}{l}\mathrm{TS}-\sqrt{ } \\
\mathrm{SS}-\sqrt{ } \\
\mathrm{CS}-\mathrm{X}\end{array}$ & $U-\sqrt{ }$ & Coh $-\sqrt{ }$ & Comp $-\sqrt{ }$ \\
\hline TEXT 6 & $\begin{array}{l}\text { In }-\sqrt{ } \\
\text { Bo }-\sqrt{ } \\
\text { Con }-X\end{array}$ & $\begin{array}{l}\mathrm{TS}-\sqrt{ } \\
\mathrm{SS}-\sqrt{ } \\
\mathrm{CS}-\mathrm{X}\end{array}$ & $U-V$ & Coh $-\sqrt{ }$ & Comp $-\sqrt{ }$ \\
\hline TEXT 7 & $\begin{array}{l}\text { In }-\varnothing \\
\text { Bo }-\varnothing \\
\text { Con }-X\end{array}$ & $\begin{array}{l}\mathrm{TS}-\varnothing \\
\mathrm{SS}-\varnothing \\
\mathrm{CS}-\mathrm{X}\end{array}$ & $U-V$ & Coh $-\sqrt{ }$ & Comp $-\sqrt{ }$ \\
\hline TEXT 8 & $\begin{array}{l}\text { In }-\sqrt{ } \\
\text { Bo }-\sqrt{ } \\
\text { Con }-\sqrt{ }\end{array}$ & $\begin{array}{l}\mathrm{TS}-\sqrt{ } \\
\mathrm{SS}-\sqrt{ } \\
\mathrm{CS}-\mathrm{X}\end{array}$ & $U-V$ & Coh $-\sqrt{ }$ & Comp - X \\
\hline TEXT 9 & $\begin{array}{l}\text { In }-\sqrt{ } \\
\text { Bo }-\sqrt{ } \\
\text { Con }-\sqrt{ }\end{array}$ & $\begin{array}{l}\mathrm{TS}-\sqrt{ } \\
\mathrm{SS}-\sqrt{ } \\
\mathrm{CS}-\mathrm{X}\end{array}$ & $U-\sqrt{ }$ & Coh $-\mathrm{X}$ & Comp - X \\
\hline TEXT 10 & $\begin{array}{l}\text { In }-\sqrt{ } \\
\text { Bo }-\sqrt{ } \\
\text { Con }-X\end{array}$ & $\begin{array}{l}\mathrm{TS}-\varnothing \\
\mathrm{SS}-\sqrt{ } \\
\mathrm{CS}-\mathrm{X}\end{array}$ & $U-X$ & Coh $-\mathrm{X}$ & Comp - X \\
\hline TEXT 11 & $\begin{array}{l}\text { In }-\sqrt{ } \\
\text { Bo }-\sqrt{ } \\
\text { Con }-\sqrt{ }\end{array}$ & $\begin{array}{l}\mathrm{TS}-\sqrt{ } \\
\mathrm{SS}-\sqrt{ } \\
\mathrm{CS}-\varnothing\end{array}$ & $U-V$ & Coh $-\mathrm{X}$ & Comp - X \\
\hline TEXT 12 & $\begin{array}{l}\text { In }-\sqrt{ } \\
\text { Bo }-\sqrt{ } \\
\text { Con }-X\end{array}$ & $\begin{array}{l}\mathrm{TS}-\sqrt{ } \\
\mathrm{SS}-\sqrt{ } \\
\mathrm{CS}-\mathrm{X}\end{array}$ & $U-V$ & Coh $-\sqrt{ }$ & Comp $-\sqrt{ }$ \\
\hline TEXT 13 & $\begin{array}{l}\text { In }-\sqrt{ } \\
\text { Bo }-\sqrt{ } \\
\text { Con }-X\end{array}$ & $\begin{array}{l}\mathrm{TS}-\sqrt{ } \\
\mathrm{SS}-\sqrt{ } \\
\mathrm{CS}-\sqrt{ }\end{array}$ & $U-V$ & Coh $-\sqrt{ }$ & Comp $-\sqrt{ }$ \\
\hline TEXT 14 & $\begin{array}{l}\text { In }-\sqrt{ } \\
\text { Bo }-\sqrt{ } \\
\text { Con }-X\end{array}$ & $\begin{array}{l}\mathrm{TS}-\sqrt{ } \\
\mathrm{SS}-\sqrt{ } \\
\mathrm{CS}-\mathrm{X}\end{array}$ & $U-\sqrt{ }$ & Coh $-\sqrt{ }$ & Comp $-\sqrt{ }$ \\
\hline TEXT 15 & $\begin{array}{l}\text { In }-\varnothing \\
\text { Bo }-\sqrt{ } \\
\text { Con }-X\end{array}$ & $\begin{array}{l}\mathrm{TS}-\sqrt{ } \\
\mathrm{SS}-\sqrt{ } \\
\mathrm{CS}-\sqrt{ }\end{array}$ & $U-V$ & Coh $-\sqrt{ }$ & Comp $-\sqrt{ }$ \\
\hline TEXT 16 & $\begin{array}{ll}\text { In } & -\sqrt{ } \\
\text { Bo } & -\sqrt{ }\end{array}$ & $\begin{array}{l}\mathrm{TS}-\sqrt{ } \\
\mathrm{SS}-\varnothing\end{array}$ & $U-\sqrt{ }$ & $\operatorname{Coh}-\sqrt{ }$ & Comp $-\sqrt{ }$ \\
\hline
\end{tabular}




\begin{tabular}{|c|c|c|c|c|c|}
\hline & Con - V & $\mathrm{CS}-\mathrm{X}$ & & & \\
\hline TEXT 17 & $\begin{array}{ll}\text { In } & -\sqrt{ } \\
\text { Bo } & -\sqrt{ } \\
\text { Con } & -\sqrt{ }\end{array}$ & $\begin{array}{l}\mathrm{TS}-\sqrt{ } \\
\mathrm{SS}-\sqrt{ } \\
\mathrm{CS}-\mathrm{X}\end{array}$ & $U-\sqrt{ }$ & Coh $-\mathrm{X}$ & Comp $-\sqrt{ }$ \\
\hline TEXT 18 & $\begin{array}{l}\text { In }-\sqrt{ } \\
\text { Bo }-\sqrt{ } \\
\text { Con }-\sqrt{ }\end{array}$ & $\begin{array}{l}\mathrm{TS}-\sqrt{ } \\
\mathrm{SS}-\sqrt{ } \\
\mathrm{CS}-\sqrt{ }\end{array}$ & $U-V$ & Coh $-\sqrt{ }$ & Comp $-\sqrt{ }$ \\
\hline TEXT 19 & $\begin{array}{l}\text { In }-\sqrt{ } \\
\text { Bo }-\sqrt{ } \\
\text { Con }-\sqrt{ }\end{array}$ & $\begin{array}{l}\mathrm{TS}-\sqrt{ } \\
\mathrm{SS}-\sqrt{ } \\
\mathrm{CS}-\sqrt{ }\end{array}$ & $U-\sqrt{ }$ & Coh $-\sqrt{ }$ & Comp $-\sqrt{ }$ \\
\hline TEXT 20 & $\begin{array}{l}\text { In }-\sqrt{ } \\
\text { Bo }-\sqrt{ } \\
\text { Con }-X\end{array}$ & $\begin{array}{l}\mathrm{TS}-\varnothing \\
\mathrm{SS}-\varnothing \\
\mathrm{CS}-\varnothing\end{array}$ & $U-X$ & Coh $-\mathrm{X}$ & Comp - X \\
\hline TEXT 21 & $\begin{array}{ll}\text { In } & -\sqrt{ } \\
\text { Bo } & -\sqrt{ } \\
\text { Con } & -\sqrt{ }\end{array}$ & $\begin{array}{l}\mathrm{TS}-\sqrt{ } \\
\mathrm{SS}-\sqrt{ } \\
\mathrm{CS}-\varnothing\end{array}$ & $U-V$ & Coh $-\sqrt{ }$ & Comp $-\sqrt{ }$ \\
\hline TEXT 22 & $\begin{array}{ll}\text { In } & -\sqrt{ } \\
\text { Bo } & -\sqrt{ } \\
\text { Con } & -\sqrt{ }\end{array}$ & $\begin{array}{l}\mathrm{TS}-\sqrt{ } \\
\mathrm{SS}-\sqrt{ } \\
\mathrm{CS}-\sqrt{ }\end{array}$ & $U-\sqrt{ }$ & Coh $-\sqrt{ }$ & Comp $-\sqrt{ }$ \\
\hline TEXT 23 & $\begin{array}{l}\text { In }-\sqrt{ } \\
\text { Bo }-\sqrt{ } \\
\text { Con }-X\end{array}$ & $\begin{array}{l}\mathrm{TS}-\varnothing \\
\mathrm{SS}-\varnothing \\
\mathrm{CS}-\mathrm{X}\end{array}$ & $U-\sqrt{ }$ & Coh $-\sqrt{ }$ & Comp $-\sqrt{ }$ \\
\hline TEXT 24 & $\begin{array}{l}\text { In }-X \\
\text { Bo }-\sqrt{ } \\
\text { Con }-X\end{array}$ & $\begin{array}{l}\mathrm{TS}-\sqrt{ } \\
\mathrm{SS}-\sqrt{ } \\
\mathrm{CS}-\mathrm{X}\end{array}$ & $U-\sqrt{ }$ & Coh $-\mathrm{X}$ & Comp $-\sqrt{ }$ \\
\hline TEXT 25 & $\begin{array}{l}\text { In }-\sqrt{ } \\
\text { Bo }-\sqrt{ } \\
\text { Con }-X\end{array}$ & $\begin{array}{l}\mathrm{TS}-\sqrt{ } \\
\mathrm{SS}-\varnothing \\
\mathrm{CS}-\mathrm{X}\end{array}$ & $U-X$ & Coh $-\sqrt{ }$ & Comp $-\sqrt{ }$ \\
\hline TEXT 26 & $\begin{array}{l}\text { In }-\sqrt{ } \\
\text { Bo }-\sqrt{ } \\
\text { Con }-X\end{array}$ & $\begin{array}{l}\mathrm{TS}-\mathrm{X} \\
\mathrm{SS}-\sqrt{ } \\
\mathrm{CS}-\mathrm{X}\end{array}$ & $U-\sqrt{ }$ & Coh $-\sqrt{ }$ & Comp - X \\
\hline TEXT 27 & $\begin{array}{ll}\text { In } & -\sqrt{ } \\
\text { Bo } & -\sqrt{ } \\
\text { Con } & -\sqrt{ }\end{array}$ & $\begin{array}{l}\mathrm{TS}-\varnothing \\
\mathrm{SS}-\sqrt{ } \\
\mathrm{CS}-\mathrm{X}\end{array}$ & $U-\sqrt{ }$ & Coh $-\sqrt{ }$ & Comp $-\sqrt{ }$ \\
\hline TEXT 28 & $\begin{array}{l}\text { In }-\sqrt{ } \\
\text { Bo }-\sqrt{ } \\
\text { Con }-X\end{array}$ & $\begin{array}{l}\mathrm{TS}-\varnothing \\
\mathrm{SS}-\varnothing \\
\mathrm{CS}-\mathrm{X}\end{array}$ & $U-\sqrt{ }$ & Coh $-\mathrm{X}$ & Comp - X \\
\hline TEXT 29 & $\begin{array}{ll}\text { In } & -\sqrt{ } \\
\text { Bo } & -\sqrt{ } \\
\text { Con } & -\sqrt{ }\end{array}$ & $\begin{array}{l}\mathrm{TS}-\sqrt{ } \\
\mathrm{SS}-\sqrt{ } \\
\mathrm{CS}-\sqrt{ }\end{array}$ & $U-V$ & Coh $-\sqrt{ }$ & Comp $-\sqrt{ }$ \\
\hline TEXT 30 & $\begin{array}{l}\text { In }-\sqrt{ } \\
\text { Bo }-\sqrt{ } \\
\text { Con }-X\end{array}$ & $\begin{array}{l}\mathrm{TS}-\sqrt{ } \\
\mathrm{SS}-\sqrt{ } \\
\mathrm{CS}-\mathrm{X}\end{array}$ & $U-\sqrt{ }$ & Coh $-\sqrt{ }$ & Comp $-\sqrt{ }$ \\
\hline TOTAL & $\begin{array}{ll}\text { In } & -\sqrt{(26)} \\
& -X(02) \\
& -\varnothing(02) \\
\text { Bo } & -\sqrt{ }(28) \\
& -X(00) \\
& -\varnothing(02) \\
\text { Con } & -\sqrt{ }(20) \\
& -X(08) \\
& -\varnothing(02) \\
\end{array}$ & $\begin{array}{ll}\text { TS- } & (21) \\
& -X(01) \\
& -\varnothing(08) \\
\text { SS } & -\sqrt{ }(23) \\
& -X(00) \\
& -\varnothing(07) \\
C S & -\sqrt{ }(07) \\
& -X(19) \\
& -\varnothing(04) \\
& \end{array}$ & $\begin{array}{l}U-\sqrt{ }(25) \\
U-X(05) \\
U-\varnothing(00)\end{array}$ & $\begin{array}{l}\mathrm{Coh}-\sqrt{ }(19) \\
\mathrm{Coh}-\mathrm{X}(11) \\
\mathrm{Coh}-\varnothing(00)\end{array}$ & $\begin{array}{l}\text { Comp }-\sqrt{ }(21) \\
\text { Comp }-X(09) \\
\text { Comp }-\varnothing(00)\end{array}$ \\
\hline
\end{tabular}




\begin{tabular}{l|ll}
\hline & & \\
& $\sqrt{ }$ & -Well-written/exist in the essay \\
$\mathrm{X}$ & -Missing \\
$\varnothing$ & -Not well-written/Not enough/wrongly framed \\
KEY: & In & -Introduction \\
Bo & -Body \\
Con & -Conclusion \\
S & -Topic Sentence \\
SS & -SupportingSentences \\
CS & -Concluding Sentences \\
U & -Unity \\
Coh & -Coherence \\
Comp & -Completeness \\
\end{tabular}

Table 1 illustrates analysis of data collected from the student participants. On introduction, 26 (86.6\%) of the essays of the participants had well-written introductions, $2(6.7 \%)$ did not have introductions, and $2(6.7 \%)$ composed wrong introductions. Concerning the body of the essay, 28 (93.3\%) had well-composed essay, and $2(6.7 \%)$ composed their essays badly. About conclusion of essays, $20(66.7 \%)$ had well-written conclusions in their essays, $8(26.7 \%)$ did not conclude their essays, and $2(6.6 \%)$ concluded their essays poorly. Furthermore, Table 1 illustrates data on topic, supporting, and concluding sentences. On topic sentence, 21 (70\%) used topic sentences in their paragraphs, $1(3.3 \%)$ essay did not have topic sentences in the paragraphs, and $8(26.7 \%)$ composed incorrect topic sentences. On supporting sentence, $23(76.7 \%)$, of the participants supported the topic sentences in the paragraphs of their essays correctly, and $7(23.3 \%)$ composed wrong supporting sentences. For concluding sentence, 7 (23.3\%) concluded the paragraphs in their essays appropriately, 19 (63.4\%) could not draw conclusions for paragraphs in their essays, and $4(13.3 \%)$ composed faulty concluding sentences. Table 1 also showcases information on paragraph unity, coherence, and completeness. On unity, 25 (83.3\%) composed essays that have paragraph unity, and $5(16.7 \%)$ composed essays with faulty unity. About coherence, as $19(63.4 \%)$ composed essays or paragraphs that had coherence, $11(36.6 \%)$ of the 30 essays did not exhibit coherence. Moreover, 21 (70\%) essays demonstrated paragraph completeness, but $9(30 \%)$ essays failed to exhibit paragraph completeness in their essays.

\section{Analysis of Paragraphs from a Native and a Non-Native Scholar of English}

This section focuses on analysisof a paragraph each from a native and a non-native scholar of English. To some extent, the analyses of the two paragraphs served as a confirmatory study to the texts collected from the classroom. 
Table 2

The Paragraph of a Non-Native Scholar of English (NNSE)

Some lecturers deliver reading from prepared notes, whilst others deliver extempore. Extempore lectures are generally more easily accessible to students because they have the oral communication features. These include repetition, simple vocabulary and syntax and non-verbal resources. Extemporised lectures are also quite personal, and the lecturer can restate his information in response to students' facial expressions, questions and other kinds of feedback. Read lectures have features of both the written and the spoken, and may have its own problems. It is written - with the features of the written code - complex sentences etc. but is rendered in speech. It is evident from the above that students have a greater access to extemporised lectures. Generally they are able to follow the thread of such lectures. Consequently, better notes can easily be taken in the extemporised lectures than in the read ones. The repetition of facts in the extemporised allows the student to add more facts to points already noted. ... (Sekyi-Baidoo, 2003, p. 115).

Sekyi-Baidoo's paragraph (see Table 2) clearly conforms to the typical structure of paragraphing - topic sentence, supporting sentences and concluding sentence - as portrayed by writers such as: Forlini et al. (1987), Warriner (1988) Childs et al. (1999) and Beare (2012). The ideas in the topic sentence - Some lecturers deliver reading from prepared notes, whilst others deliver extempore - have been exhaustively expatiated by convincing supporting sentences. The paragraph also possesses all the three elements - unity, coherence and completeness - that a paragraph is expected to have.

Table 3

The paragraph of a native scholar of English (NSE)

Many people find it difficult to do the intense, active thinking that clear writing demands. It is frightening to sit down before a blank sheet of paper and know that an hour later, nothing on it may be worth keeping. It is frustrating to discover how much of a challenge it is to transfer thoughts and feelings from one's head onto a sheet of paper. It is upsetting to find that an apparently simple subject often turns out to be complicated. But writing is not an automatic process: we will not get something for nothing - and we should not expect to. For almost everyone, competent writing comes from plain hard work - from determination, sweat, and head-on battle. The good news is that the skill of writing can be mastered, and if you are ready to work, you will learn what you need to know. (Langan, 2001, p. 13).

John Langan's paragraph (Table 3) on the other hand illustrates how ingenious native speakers or scholars of English could be when it comes to paragraphing. The topic sentence, many people find it difficult to do the intense, active thinking that clear writing demands, has been convincingly supported by simple sentences. The paragraph also ends with a clincher. Elements of paragraphing - unity, coherence, and completeness - are also evident in the text in question.

\section{The Findings}

Table 4 gives a representation of analysis of students' data. It (Table 4) provides us with answers to RQ 1,2 and 3. It is observed that 26 out of 30 students $(86.7 \%)$ included introduction in their essays. Twenty (20) (66.7\%) included conclusion, 21 (70\%) and 23 (76.7\%) did not have topic and supporting sentences problems respectively, and only 7 (23\%) included concluding 
sentences in their paragraphs. Again, the essays of $25(83 \%)$ students did not have unity problems. Also, as 19 (63\%) essays had coherence, 21 (70\%) essays had completeness. The findings have been written in a way to answer the research questions of the study:

Table 4

Essay Structure and Paragraph Theory in students' essays

\begin{tabular}{lcc}
\hline Essay Structure/ Paragraph Theory & $\begin{array}{c}\text { No. of Students who used various } \\
\text { paragraph features }\end{array}$ & Percentage $\%$ \\
\hline Introduction & $26 / 30$ & 86.7 \\
Body & $28 / 30$ & 93 \\
Conclusion & $20 / 30$ & 66.7 \\
Topic Sentence & $21 / 30$ & 70 \\
Supporting Sentences & $23 / 30$ & 76.7 \\
Concluding Sentences & $07 / 30$ & 23.3 \\
Unity & $25 / 30$ & 83 \\
Coherence & $19 / 30$ & 63 \\
Completeness & $21 / 30$ & 70 \\
TOTAL & 30 & $100 \%$ \\
\hline
\end{tabular}

\section{Discussion}

In answering RQ1, it is obvious that students' essays possess introduction $(86.7 \%)$ and conclusion (66.7\%). However, the study tested only the inclusion of introductions and conclusions in students' essays. It did not examine the various sentences in the introductions and conclusions. For example, Langan (2001) and Lane (2004) as cited in Owusu \& Adade-Yeboah (2014, p.56-57) have indicated that an introduction of an essay should possess a catchy sentence, a thesis statement and a plan of development. And conclusions should have a summary and general remarks. Therefore, in future, a study will be needed to examine the sentences in the introductions and conclusions of students' essays. Such a study may focus on the inclusion or otherwise of these vital sentences that are expected to be utilized in composing introductions and conclusions of essays. In answering RQ2, it was found that the paragraphs of students have topic sentences $(70 \%)$, which are corroborated with supporting sentences $(76.7 \%)$. However, students have challenges with concluding sentence (which is supposed to be the final item in each paragraph of an essay). Thus, only $7(23.3 \%)$ out of 30 scripts had paragraphs ending with concluding sentences. Warriner (1988) has stressed the importance of concluding sentence in every paragraph and has even referred to it as clincher - a fact that settles a matter conclusively. Therefore, in the teaching and learning of essays and paragraph theories, attention should be placed on concluding sentence. On RQ3, the paper found out that though, students composed essays that contained $83 \%$ paragraph unity, attention should be paid to how to maintain coherence in essays. Thus, inclusion of coherence formed $63 \%$. Though $63 \%$ is not a bad reflection of students' performance on coherence; the remaining $37 \%$ of the essays that did not include coherence must be a good reason for language teachers to focus attention on coherence additionally. Coherence is useful in building logical bridges in essays. Driscoll and Brizee (2010) as cited in Owusu (2015, p. 122) suggests ways of building logical bridges as: reiterating key words in sentences, repeating synonymous in several sentences, using anaphoric and cataphoric pronoun referencing in previous sentences of paragraphs, and using transitional devices to link 
ideas from different sentences. On RQ4, the literature review and the paragraphs of NNSE and NSE proved that paragraph theories are not array of impressions per se, though there are few conflicting ideas. For example, the literature on structure of the paragraph (for example, Forlini et al., 1987, Warriner, 1988 Childs et al., 1999 and Beare, 2012; Driscoll \& Brizee, 2010) creates the impression that all paragraphs should have this structure - topic sentence, supporting sentences and concluding sentence. But, this is not so as Lunsford \& Connors (1995, p. 116), have defined paragraph as 'a group of sentences or a single sentence that forms a unit.' If a single sentence can form a paragraph, then obviously, that paragraph cannot have supporting sentences and a concluding sentence. Though, this normally creates confusion in the minds of young second language learners, one cannot conclude that paragraph theories are mere collection of ideas. The study, consequently, elicited various grammatical errors in the students'paragraphs. Though the focus of the study was on parapraph issues, these grammatical errors are worthy of mentioning. Grammatical errors, also known as usage errors, grammar errors, bad grammar, are used in prescriptive grammar to describe an instance of defective, unusual, or contentious usage (Norquist, 2019b). Several grammatical errors abound. Notably among them which were found in texts of the student participants are: semantic or misplaced modifier errors, spelling, punctuation, verb tense errors, and concord errors. In semantic/misplaced modifier error, a word, phrase, or clause is mistakenly separated from the word it describes. Errors of this nature normally affect comprehension. From the data collected, some of these errors were captured:

1. Crossing the road, many people were seen (Crossing the road, I saw many faces).

2. Having seen the lady, her beauty attracted me.(Having seen the lady, Kwame was attracted by her beauty).

3. Seeing the boy, the money was given to him (Seeing the boy, Ama gave him the money).

4. I saw the boy in the valley standing on top of the hill(Standing on top of the hill, I saw the boy).

5. Running to town, a snake nearly bit Yaw(Running to town, Yaw was nearly bitten by a snake).

6. Kofi left the house and took a walk scolded by his father(Scolded by his father, Kofi left the house and took a walk).

In example 1, 2, and 3, the subjects were missing from the structures. Therefore, there was the need to introduce the true subjects - I, Kwame, and Ama respectively. In examples 4, 5, and 6, the true subjects: I, Yaw, and Kofi had to be repositioned for the ambiguity to be cleared. Furthermore, errors associated with spelling were also identified in the data collected:

7. Expireing (expiring), limitted (limited), proceedere (procedure), openning (opening), clossing (closing), wonda (wonder), abolt (about), numberng (numbering), infact (in fact), dinninghall (dining hall), usuall (usual), maneger (manager), livel (level), hopeing (hoping), manegment (management), conveged (conveyed), pistle (pestle), accross (across), mordern (modern), gorveing (governing), preperation (preparation).

The data also showed several punctuation errors:

I will write to you in one week time. (I will write to you in one week's time.); the company goods... (the company's goods...); lets all... (let's all...); ...are listed below; (...are listed below:), the manager office (the Manager's office); after this process they are ... (after this 
process, they are...); Your's faithfully, (Yours faithfully,).

Errors of verb tense were also found in the students' scripts: We went to the market to purchased(We went to the market to purchase); Our documents are process... (Our documents are processed...); We have take delivery... (We have taken delivery...); All customers are expect to pay... (All customers are expected to pay...); The company have... (The company has...); our company didn't knew about... (our company didn't know about...); my company process... (my company processes...); how foods is processed. (how foods are processed.); It has being observed... (It has been observed...).

The students also committed concord errors: How food are...(How foods are.../How food is...), these cage (these cages...), one of the best company... (one of the best companies...), all member... (all members...), to reminded... (to remind...).

\section{Implications and Suggestions for Future Research}

Based on the analyses, findings and discussions, some suggestions have been made for future research. One, In the teaching and learning of paragraphing, a lot of attention should be paid to concluding sentences. This is because only 7 (23.3\%) out of 30 student-participants ended the various paragraphs in their essays with concluding sentences. This situation connotes that most students are oblivious of the role concluding sentences play in paragraphs. It could also be that students know of the impotance of concluding paragraphs, but they feel concluding paragraphs may be optional in classroom settings. This is so, especially when they (students) read structures by language scholars, which do not have concluding sentences. This situation mostly elicits a lot of questions from students when language teachers teach paragraphing in class.

Again, the research revealed various coherence errors of students. Language teachers should therefore pay attention to coherence, since some (11 students) of the participants could not display dexterity in this area.This proposition does not suggest that language teachers have done little in this area. The suggestion simply seeks to encourage language teachers to do more work on teaching and grading of coherent issues in discourse studies. Thus, students need to be conscientized about the imperativeness of coherence in most discourse studies.

Though 26 participants (86.7\%) introduced essays with various introductions, and 20 (66.7\%) concluded essays in various ways, since the current study failed to account for the constituents ofintroductions and conclusionsin students'composition, I recommend more research studiesto be conducted in these areas. Such studieswould perusethe composition of sentences for introductions and conclusions in students' essays.Furthermore, because the study exposed various sentential problems of students, more research works on students' sentential problems are recommended.

\section{Conclusion}

Paragraphing is an important area in Second Language Studies. According to Owusu (2015, p. 124), it helps the writer to organise his discourse; it helps the reader in identifying one point of an issue from another; it encourages the writer to give adequate focus to the various aspects of his message; and it helps the reader to skim long passages. The current research aimed at 
responding to the question about whether 'paragraph theories are array of impressions?' The study was necessitated by the fact that most students become confused anytime they read conflicting issues on paragraph theory. The study, therefore, looked at theories of paragraph that have been advocated by some authorities and writers in the fields of discourse analysis, essay writing, critical review, and research studies. Data that were collected and analysed from the field, exposed paragraph writing flaws of students. For example, out of 30 scripts analysed, only $7(23.3 \%)$ included concluding sentences in their essays. Again, the participants did not perform better on sentence coherence and completeness. Though, the study did not trace sources of students' paragraphing errors, what might have accounted for these flaws are students' exposure to paragraphs in some texts (essays) that do not possess concluding sentences. Again, some issues on paragraph theory are diametrically opposed. For example, Langan $(2001$, p.5) defines a paragraph as a short paper of about 150 to 200 words, which consists of a topic sentence and supporting sentences. Lunsford \& Connors' (1995, p. 116) claim that a paragraph can be made up of only a single sentence. Though it is a truism, that not all texts will have paragraphs may contain all elements and parts of the paragraph theory (such as: topic sentence, supporting sentences, concluding sentence, unity, coherence, and completeness) as stated in Beare (2012), Rolls \& Wignell (2013) and Nordquist (2019a); students become confused when they realise that some paragraph features are missing from the essays of some scholars. It is for this reason that a paragraph each from a native and a non-nature speaker of English was analysed. The finding of that analysis showed that paragraph theories are not array of impressions per se, since contextual issues and different write-up conventions may prevent a writer from using one or two of some features of the paragraph theory.

The study recommends that language teachers should pay a closer look at concluding sentences anytime teachers teach paragraph theory in various classrooms. Furthermore, there is the need for modern authors to synchronize the various incoherent issues of authorities on paragraph theory and make a move towards advancing more unified issues on the paragraph theory.

\section{References}

Adade-Yeboah, A. \& Owusu, E. (2016). An assessment of the methods of development in the essays of business students in Ghanaian private universities: A case study. Open Access Library Journal, 3: e3176, http://dx.doi.org/10.4236/oalib.1103176

Bauman, G. M. (1991). Ideas and details: A guide to college writing. Florida: Harcourt Brace Jovanovich Inc.

Beare, K. (2012). Paragraph writing. English as second language. Retrieved fromwww.els.about.com/cs/writing

Carroll, A. J., Wilson, E. E.,\& Forlini, G. (2001). Writing and grammar: Communication in action, (Bronze Level). New Jersey: Prentice-Hall Inc.

Childs, L., Acott-Smith, A.,\& Curtis, K. (1999). Writing paragraphs and the writing process. Academic Studies English. Retrieved from http://www.nald.ca/library/learning/academic/english/writing.

Downing, A. \& Locke, P. (2006). English grammar: A university course (2nd ed.). New York, USA: Routledge Taylor and Francis Group.

Driscoll, D. L. \& Brizee, A. (2010). On paragraphs. Retrieved from www.owl.english.purdue.edu 
Forlini, G., Bauer, M. B., Biener, L., Capo, L., Kenyon, K. M., Shaw, D. H., \& Verner, Z. (1987). Grammar and composition (3rd ed.). Englewood Cliffs, New Jersey: Prentice-Hall, Inc.

Halliday, M. A. K. \& Hasan, R. (1976). Cohesion in English. England: Pearson Education Limited.

Jerz, D. G. (2011, February 18). Thesis Statements: How to write them in academic essays[Blog post]. Retrieved from www.jerz.setonhill.edu/.../thesis-statement-writing-academic-essays

Johnson, T. (2004, January 29). Ten steps to writing an essay[Blog post]. Retrieved from www.aucegypt.edu/academic/writers

Kirzner, L. G. \& Mandell, S. R. (2007). The Holt handbook (4th ed.). Fort Worth: Harcourt Brace College Publishers.

Langan, J. (2001). College writing skills with readings(5th ed.). New York, USA: McGraw-Hill Companies Inc.

Lunsford, A. \& Connors, R. (1995). The St. Martin's handbook - Annotated instructor's edition. New York, USA: St. Martins.

Nordquist, R. (2019a). Definitions and examples of paragraphing in essays. Retrieved from https://www.thoughtcom.com>paragraphing-composition-term-1691483

Nordquist, R. (2019b). What is a grammatical error? Retrieved from https://www.thoughtcom.com/grammatical_ error-usage-1690911

Owusu, E. (2015). Modern business communication(3rd ed.). Kumasi, Ghana: Maciv Business Consult.

Owusu E. (2012). Assessing the methods of development in the compositions of students in universities in Ghana: The case of Christian Service and Ghana Baptist University Colleges, Kumasi (MPhil Thesis). University of Ghana, Department of Linguistics, Legon, Ghana.

Owusu, E. \& Adade-Yeboah, A. (2012). Thesis statement: A vital element in expository essays. Journal of Language Teaching and Research, Vol. 5, No. 1, pp. 56-62. doi.10.4304/j1tr.5.1.56-62. Retrieved from www.academypublication.com

Rolls, N. \& Wignell, P. (2013). Communicating at university: Skills for success. Darton, Australia, Charles Darwin University Press

Rosen, L. \& Laurence, B. (1997). The Allyn and Bacon Handbook - Annotated instructor's edition (3rd ed.).Boston, USA: Allyn and Bacon.

Samuels, H. (2004, February 24). Writing a thesis statement [Blog post]. Retrieved from www.crlsresearchguide.org/13_thesis_statement

Sekyi-Baidoo, Y. (2003). Learning and communicating. Accra, Ghana: Passion Printing Press.

Seliger, H. W. \& Shohamy, E. (2001). Second language research. Oxford, UK: Oxford University Press.

Stern, A. A. (1976). When is a paragraph?College Composition and Communication, Vol. 27, No. 3, $253-257$. Retrieved from http://www.jstor.org/stable/357044

Tagg, J .(2004). Discovering ideas handbook: The thesis statement. Retrieved from www.daphne.palomar.edu/handbook/thesis.hitm

Warriner, J. E. (1988). English composition and grammar: Second course (Benchmark ed.). Florida: Harcourt Brace Jovanovich, Inc. 